
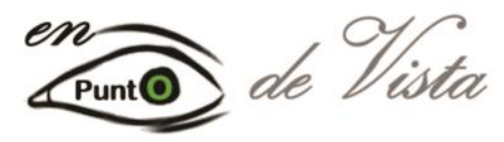

\title{
Concepções sobre analogias no discurso de professores de Química
}

\section{Rosiane Alexandre Pena Guimarães ${ }^{1}$, Kalmon da Silva Oliveira², Marcel Thiago Damasceno Ribeiro $^{3}$}

\author{
${ }^{1}$ Graduada em Química pela Universidade Federal do Mato Grosso (UFMT/Brasil). \\ ${ }^{2}$ Graduado em Ciências Físicas e Biológicas pela Universidade de Cuiabá (UNIC/Brasil). \\ ${ }^{3}$ Doutor em Educação em Ciências e Matemática pela Universidade Federal de Mato Grosso \\ (UFMT/REAMEC).
}

Professor dos Programas de Pós-Graduação em Educação (PPGE/UFMT) e Ensino de Ciências Naturais (PPGECN/UFMT).

\section{Conceptions about Analogies in the Speech of Chemistry Teachers}

\section{Informações do Artigo}

Recebido: $25 / 05 / 2020$

Aceito: $22 / 06 / 2020$

Palavras chave: ensino de ciências; analogias; ensino de química

\section{Key words:}

science teaching; analogies; chemistry teaching

E-mail: rosianepena@hotmail.com

\begin{abstract}
A B S T R A C T
Analogies are configured as an important tool for understanding complex concepts in the classroom. In addition, the use of analogies can facilitate the process of appropriating new concepts, since this teaching strategy establishes comparisons between two domains, one known and the other unknown. Due to the role played by this instrument, it is necessary to know the teachers' previous conceptions about the theme. For this, a qualitative study was carried out, through the Case Study, using the questionnaire and semi-structured interview as a collection instrument, applied to six professors who graduated from the professional master's degree in Science Teaching in the area of Chemistry. As a result, some difficulties were noticed, such as conceptualizing analogies and differences between analogies and metaphors. Thus, it became evident the need to insert discussions about the use of analogies in teaching, emphasizing its function, its uses, its advantages and disadvantages.
\end{abstract}

\section{INTRODUÇÃO}

O objetivo do Ensino de Ciências é a formação de cidadãos pensantes e atuantes, no destino de uma sociedade. É por meio desse ensino que os estudantes podem desenvolver um pensamento de observação, de investigação e de reflexão, proporcionando, assim, melhor convívio na sociedade. Oferecer instrumentos para que o aluno possa fazer uma reflexão desses conhecimentos adquiridos, tornando-o dono de suas próprias ações, sendo um dos principais objetivos de se ensinar Ciências nas escolas (COELHO et al. 2015).

Ciente disto, o professor como guia e orientador do processo de ensino e aprendizagem, deve buscar estratégias que visem facilitar a aquisição de novos conhecimentos por parte dos estudantes, e que consigam despertar o interesse, a curiosidade e a motivação desses pelo assunto trabalhado, de modo que possam, de maneira racional, fazer interpretação lógica de determinados acontecimentos. Para Bizzo (2002, p. 14): “o ensino de Ciências deve proporcionar a 


\section{Educação Química}
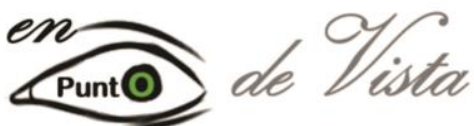

\section{Chemical Education in Point of View}

https://revistas.unila.edu.br/eqpv

todos os estudantes a oportunidade que eles despertem a inquietação diante do desconhecido, buscando explicações lógicas e razoáveis amparadas em elementos tangíveis.

Nesse âmbito se enquadram as analogias, que podem ser uma opção de abordagem para trabalhar os conteúdos de Ciências, em sala de aula, de forma mais dinâmica e atrativa para os estudantes.

Nos últimos anos, estudos sobre as analogias têm se intensificado por diversos pesquisadores nacionais, como: Mól (1999), Ferraz e Terrazzan (2002), Bozelli e Nardi (2005), Francisco Junior (2010), Mozzer e Justi (2015) entre outros. Esse interesse se justifica pelo fato de que as analogias fazem parte do processo cognitivo dos seres humanos e, ainda, se empregadas corretamente auxiliam para a compreensão e construção do conhecimento dos conceitos científicos.

A analogia, para além de uma mera figura de linguagem, é um instrumento de paridade, que possibilita a comparação entre algo que se conhece com o que não se conhece. Nessa perspectiva, as analogias figuram como ferramentas indispensáveis no auxílio da compreensão dos conceitos que permeiam campos abstratos da Ciência, como no caso da Química, que ancora seus conceitos em uma perspectiva bastante abstrata, surgindo como uma alternativa de ação na compreensão de conceitos científicos.

Para Rigolon e Obara (2010), as analogias são uma forma atrativa, criativa, estimulante e eficaz de promover a abstração de conhecimentos científicos, devendo ser ativado o raciocínio analógico sempre que o assunto for distante da realidade, para que haja essa mediação entre os conhecimentos já estabelecidos e os que se encontram em construção.

O desenvolvimento satisfatório das analogias, de acordo com Mozzer e Justi (2018, p. 156), possibilita: "[...] o desenvolvimento da criatividade, da imaginação, na construção de um pensamento mais interligado e no desenvolvimento de estratégias, habilidades e visões epistemológicas de interesse para a ciência [...]". Entretanto, as autoras também alertam para o fato de que essa consideração só pode ser feita desde que as analogias sejam utilizadas de forma apropriada, sistematizada e planejada, para que, de fato, redundem em uma ferramenta proveitosa.

Em função do papel ocupado pelas analogias no Ensino de Ciências, e no intuito de avançar com as discussões sobre essa temática, o presente estudo tem o objetivo identificar quais são as concepções que professores de Química, egressos do Mestrado Profissional em Ensino de Ciências, possuem sobre o uso de analogias e o seu papel no ensino.

Vale destacar que este trabalho é resultado da primeira fase de um estudo ${ }^{1}$ mais amplo intitulado: Estratégias de ensino por meio de analogias: uma proposta de guia didático para o

\footnotetext{
${ }^{1}$ Pesquisa é registrada e aprovada no Comitê de Ética de Pesquisa (CEP) Humanidades da Universidade Federal de Mato Grosso, no ano de 2020 sob o registro no CAAE: 26027219.2.0000.5690
} 


\section{Educação Química}
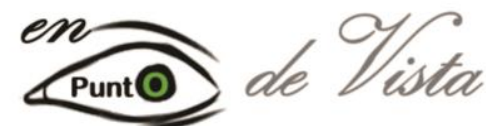

Chemical Education in Point of View

https://revistas.unila.edu.br/eqpv

ensino de Química, que se encontra em desenvolvimento no Programa de Pós-Graduação em Ensino de Ciências Naturais da Universidade Federal de Mato Grosso.

\section{FUNDAMENTAÇÃO TEÓRICA}

Na perspectiva construtivista de aquisição/construção do conhecimento, o estudante deve atribuir significado ao conhecimento que the é ensinado. E, para atribuir este significado, o estudante precisa encontrar ou criar conexões entre a nova informação e o conhecimento já existente. Uma das maneiras de tornar eficaz este processo é realizá-lo por meio do uso de analogias (ZAMBON; TERRAZZAN, 2013).

A origem do pensamento analógico está intimamente ligada ao surgimento do homem enquanto ser racional, e as primeiras teorias sobre as analogias e metáforas surgiram na Grécia, com Aristóteles (século IV a.C.), e o seu uso era considerado a marca dos gênios. Desde então, com o desenvolvimento das Ciências Cognitivas, campo multidisciplinar que integra desde a Psicologia, Filosofia da Ciência e Linguística até a Neurociência e Inteligência Artificial, as analogias passaram a ter diferentes abordagens referentes ao seu papel no processo de ensino e aprendizagem (DUARTE, 2005).

Em termos de definição, Duarte (2005), em uma ampla revisão de literatura, apresenta que para alguns autores, as analogias são entendidas como um processo cognitivo que envolve uma comparação explícita de duas coisas, uma definição de informação nova em termos já familiares. Outros autores, como Duit (1991) e Treagust et al (1992), definem as analogias como comparações baseadas em similaridades entre estruturas de domínios diferentes, sendo um conhecido e outro desconhecido. O domínio corresponde a uma área do conhecimento, podendo ser científico, no caso do domínio alvo, ou não científico, no caso do domínio análogo.

Em concordância com esses autores, Zambon e Terrazzan (2013) entendem que uma analogia é uma comparação entre conceitos/fenômenos/assuntos desconhecidos ou pouco conhecidos que mantém relações de correspondência com outras situações mais familiares e conhecidas para quem aprende.

Quanto às terminologias usadas para designar os domínios, são comuns os termos alvo, tópico, tema e foro para nominar o domínio desconhecido. Já termos como análogo, base, fonte $e$ veículo são usados para nominar o domínio conhecido. Segundo Duarte (2005), independentemente dos termos adotados, esta variedade não pressupõe divergências sobre os seus significados.

Diante dessa polissemia conceitual, para evitar confusões entre os conceitos, utiliza-se neste trabalho a terminologia proposta por Zambon e Terrazzan (2013), na qual o termo alvo é para aquele conceito, fenômeno ou assunto que se quer compreender, e o termo análogo para aquele que servirá de subsídio no alcance do primeiro. 


\section{Educação Química}
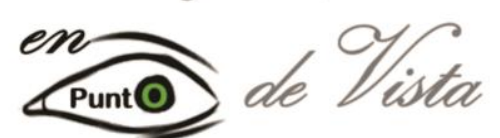

\section{Chemical Education in Point of View}

https://revistas.unila.edu.br/eqpv

É possível encontrar na literatura, além das diferentes concepções de analogia, uma grande variedade de expressões utilizadas para descrevê-las, entre essas estão: recursos didáticos (FERRAZ; TERRAZZAN, 2002), ferramenta (FERRAZ; TERRAZZAN, 2002; OLIVA, 2001; DUARTE, 2005), instrumento (MONTEIRO; JUSTI, 2001), instrumentos de cognição (FRANCISCO JÚNIOR, 2010), modelo ou estratégia de ensino (FERRY; NAGEM, 2009), figuras de linguagem (BOZELLI; NARDI, 2006), facilitadores na compreensão de abstratos (DUIT, 1991 apud BOZELLI; NARDI, 2006).

Além dessas diferenças, Duarte (2005) apresenta diferentes objetivos com os quais as analogias são usadas. Para essa autora, as analogias podem adquirir função explicativa ou comunicativa quando são usadas para tratar de correspondências entre duas situações e, podem adquirir também a função inferencial ou generativa, quando implicam a previsão de mais semelhanças a partir das existentes: [...] as analogias têm uma função explicativa, quando colocam conceitos e princípios novos em termos familiares; têm uma função criativa quando estimulam a solução de um problema, a identificação de um problema novo e a generalização de hipóteses (GLYNN et al, 1989 apud DUARTE, 2005).

Frequentemente, as analogias e as metáforas são consideradas sinônimas, entretanto, em se tratando do processo de ensino e aprendizagem é importante que os professores saibam diferenciar cada termo, para que assim as analogias sejam utilizadas corretamente em sala de aula. (OLIVA, 2001).

Para Mól (1999) e Duarte (2005) tanto as analogias como as metáforas estão subordinados a ideia de comparação, mas diferem em sua essência, ou seja, a metáfora é uma comparação implícita enquanto a analogia é uma comparação explícita e mais elaborada. De acordo com Francisco Júnior (2010, p. 64) "as analogias explicitam comparações de estruturas de dois domínios indicando partes iguais de suas estruturas", enquanto "as metáforas comparam implicitamente, salientando qualidades que não coincidem nos dois domínios". Devido ao aspecto mais sistemático, Cachapuz (1989), afirma que as analogias são geralmente mais exploradas que as metáforas nos manuais escolares de Ciências.

Por exemplo, quando o professor diz ao explicar o modelo atômico de Rutherford que os átomos são sistemas solares, ele está utilizando uma metáfora, pois está afirmando que o átomo é o sistema solar, que obviamente não é. Essa afirmação exige, de quem a recebe, a habilidade de identificar que se trata de uma metáfora, caso contrário, pensar-se-á que o átomo é o sistema solar. Já quando o professor diz que os átomos são como ou se assemelham ao sistema solar, ele faz uso de uma analogia, pois o professor compara explicitamente atributos comum aos domínios alvo e análogo, conforme no quadro 1.

Quadro 1- Atributos de correspondências na analogia sistema solar e o modelo atômico de Rutherford.

\begin{tabular}{|c|c|c|}
\hline $\begin{array}{c}\text { Alvo } \\
\text { (Modelo atômico de Rutherford) }\end{array}$ & $\begin{array}{c}\text { Análogo } \\
\text { (sistema solar) }\end{array}$ & Semelhanças \\
\hline Sol & Núcleo & Partícula central com maior massa \\
\hline
\end{tabular}




\section{Educação Química}

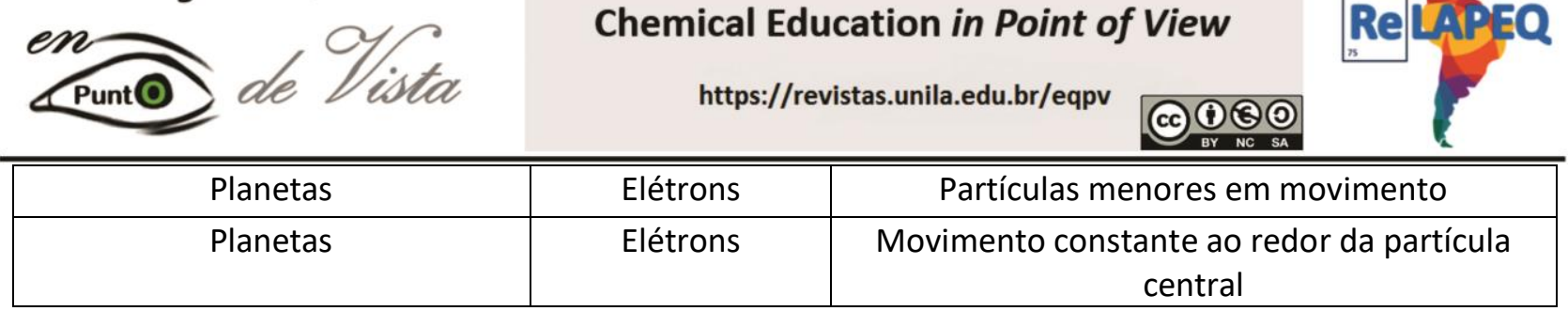

Fonte: (MÓL, 1999).

No que concerne ao Ensino de Ciências, Oliva (2001) relata que os primeiros trabalhos com interesses voltados para o estudo das analogias surgiram na década de 1960 . No entanto, somente na década de 1980 que as investigações neste campo se intensificaram. Muitas vantagens são atribuídas para o seu uso no ensino por diversos pesquisadores. Conforme Duarte $(2005$, p.11), as analogias:

1. Levam à activação do raciocínio analógico, organizam a percepção, desenvolvem capacidades cognitivas como a criatividade e a tomada de decisões; 2. Tornam o conhecimento científico mais inteligível e plausível, facilitando a compreensão e visualização de conceitos abstractos, podendo promover o interesse dos alunos;

3. Constituem um instrumento poderoso e eficaz no processo de facilitar a evolução ou a mudança conceptual;

4. Permitem percepcionar, de uma forma mais evidente, eventuais concepções alternativas;

5. Podem ser usadas para avaliar o conhecimento e a compreensão dos alunos.

Mozzer e Justi (2015), em seu trabalho, também discorrem sobre as vantagens do uso das analogias. Para essas autoras, as analogias possibilitam um melhor entendimento de conceitos e entidades abstratas pelos alunos, auxiliam na promoção de novos conhecimentos, desenvolvem a imaginação e a criatividade, além de possibilitarem a superação de concepções alternativas.

Nesse âmbito, muitos professores, ao se depararem com conceitos abstratos e difíceis em suas aulas, frequentemente, recorrem ao uso das analogias. Geralmente, partem do pressuposto de que ao lançar mão de uma analogia, o conceito se tornará mais claro e mais evidente e, consequentemente, será mais compreensível pelos estudantes, desde que os mesmos tenham feito de maneira correta as correspondências (FERRY; NAGEM, 2009).

Segundo Ferraz e Terrazzan (2002), o raciocínio por analogia é parte constituinte da cognição humana, assim sendo, as analogias se configuram como ferramentas de pensamento. Desse modo, quanto mais os conceitos forem distantes da realidade dos estudantes, mais frequente será o uso de analogias para aproximá-los do conhecimento científico.

Para que as analogias possam atuar como um recurso eficaz no processo de ensino e aprendizagem, viabilizando as vantagens citadas anteriormente, é necessário que essas sejam utilizadas de forma adequada. Caso contrário, essas analogias podem dificultar ainda mais a aprendizagem dos estudantes. Entre os riscos inerentes ao uso indiscriminado das analogias no ensino, Duarte (2005, p. 12) destaca que: 


\section{Educação Química}

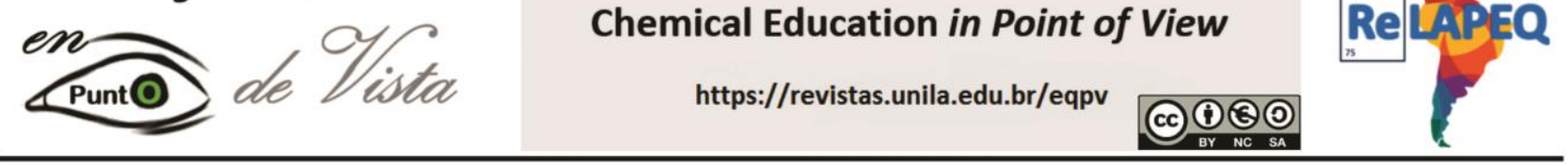

1. A analogia pode ser interpretada como o conceito em estudo, ou dela serem apenas retidos os detalhes mais evidentes e apelativos, sem se chegar a atingir o que se pretendia;

2. Pode não ocorrer um raciocínio analógico que leve à compreensão da analogia;

3. A analogia pode não ser reconhecida como tal, não ficando explícita a sua utilidade;

4. Os alunos podem centrar-se nos aspectos positivos da analogia e desvalorizar as suas limitações.

Com a intenção de auxiliar no processo de formulação dos conceitos abstratos, as desvantagens relatadas anteriormente merecem atenção especial, visto que as analogias se constituem como representações didáticas, que carreiam inerentemente simplificações. Essas simplificações, aliadas ao mal uso desse recurso desencadeiam a consolidação de ideias dissonantes das científicas, as quais pretendiam formar. Segundo Carvalho e Silveira $(2019$, p.173): "por causa da riqueza de significados que uma palavra pode ter dentro de uma língua, podem ocorrer interpretações distintas daquela que o emissor deseja transmitir". E ainda, conforme Francisco Júnior (2009, p. 122): “[...] seu emprego de forma simplificada e espontânea pode guiar o pensamento para uma visão concreta e imediata que impede a abstração necessária à formação do conhecimento científico".

Mozzer e Justi (2015) concordam com Duarte (2005), e apresentam preocupações em comum quanto ao uso indiscriminado das analogias. Entre as preocupações destacam o fato de que os professores:

[...] não possuem um repertório bem preparado e validado de analogias, tendendo a elaborá-las sem o devido cuidado, no momento mesmo em que ensinam [...] apresentam analogias como algo (um artefato, não um processo de raciocínio) pronto e acabado, capaz de "transmitir" conhecimentos para os estudantes [...] almejam que os estudantes compreendam relações analógicas que apresentam um significado claro e objetivo para eles, mas não para seus estudantes [...] selecionam análogos pouco familiares aos estudantes ou, às vezes, mais complexos do que o alvo [...] tendem a confundir as analogias com outros tipos de similaridades (como metáforas, comparações de mera aparência etc.) ou outros recursos didáticos (como exemplos e modelos) (MOZZER; JUSTI, 2015, p. 125).

Portanto, as discussões sobre o uso sistematizado das analogias devem ter um destaque central nos cursos de formação docente. O papel da linguagem é essencial no ensino de Ciências, visto que a comunicação, nesse meio, nem sempre é realizada apenas pela linguagem científica, principalmente, no contexto escolar. Segundo Flôr (2009, p. 27), em sua tese de doutorado: "reconhecer que a linguagem científica também é metafórica e se utiliza de analogias para explicar os fenômenos que trata é de fundamental importância no contexto da educação e abre caminhos para pensar a linguagem e a ciência de uma forma mais ampla". 


\section{Educação Química}
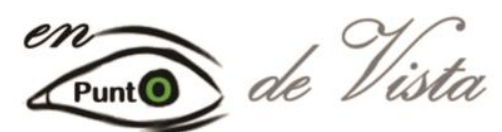

Chemical Education in Point of View

https://revistas.unila.edu.br/eqpv

Considerando a relevância de estudos que versam sobre a utilização das analogias, como importantes instrumentos nos processos de ensino e aprendizagem, têm sido elaboradas diversas propostas que se baseiam no uso deste instrumento. De acordo com Ferraz (2006), para o uso efetivo das analogias, essas devem estar dispostas de forma estruturada, seguindo uma sequência mínima de passos a serem seguidos, de maneira a minimizar a formação de concepções alternativas por parte dos estudantes.

No anseio de contribuir para uma aprendizagem mais efetiva, Oliva et al (2001, p. 459) corroboram ao dizer que: "tanto o professor como os alunos precisam dispor de elementos que Ihes permitam sistematizar o processo de construção das analogias [...]" e necessitam de um modelo que possibilite a construção de analogias em uma perspectiva crítica.

Segundo Duarte (2005), é possível agrupar os modelos de ensino com analogias em três tipos: modelos centrados no professor, modelos centrados no aluno e modelos centrados no professor e no aluno. Esses modelos, embora o foco esteja em públicos diferentes, todos trazem propostas em que as analogias têm o propósito de facilitar a compreensão dos conteúdos desconhecidos pelos estudantes.

Um dos modelos mais citados na literatura, conforme apresenta Duarte (2005) e Francisco Júnior (2010), é a proposta de Glynn (1991), o Teaching with analogies-TWA, cuja tradução é Ensinando com Analogias. Neste modelo, Glynn destaca que, quando o professor lança mão de uma analogia, é imperioso que ele acompanhe a compreensão dos estudantes frente à analogia, para que assim sejam feitas as interpretações adequadas. O modelo consiste em seis operações sequenciais que, segundo o autor, são eficazes para garantir uma interpretação adequada pelos estudantes e acrescenta que não é necessário seguir uma ordem específica para o uso do TWA, desde que todas sejam realizadas, sendo essas:

1) introduzir o conceito alvo, realizar uma explicação inicial sobre o alvo a ser ensinado;

2) relembrar o conceito alvo, recordar com os estudantes quais suas concepções sobre o conceito análogo;

3) verificar os aspectos e similaridades dos conceitos, discutir as principais características desses domínios;

4) mapear as similaridades, estabelecer as correspondências de similaridades entre os domínios;

5) tirar conclusões, extrair informações importantes sobre o domínio alvo;

6) indicar onde a analogia termina, discutir os pontos em que não há semelhança entre os domínios alvo e análogo.

Apesar de algumas limitações evidenciadas neste modelo, é possível afirmar que esta proposta TWA se constitui como uma ferramenta útil, quando se trata de auxiliar o professor em como abordar uma analogia aos estudantes. Além disso, esta proposta partilha da preocupação de explicitar o mapeamento das correspondências, assim como as limitações da analogia. 


\section{Educação Química}
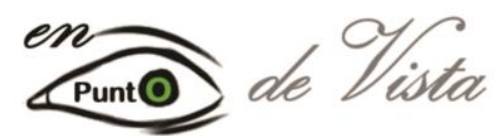

\section{Chemical Education in Point of View}

https://revistas.unila.edu.br/eqpv

São promissoras as linhas de investigação sobre o ensino com analogias. Entre essas há pesquisas como as de Ferraz e Terrazzan (2002) e Mozzer e Justi (2013), que visam identificar e mapear quais são as concepções que professores em exercício ou formação inicial como as de Oliveira e Mozzer (2017) e Rigolon e Obara (2011). Essas pesquisas indicam que as concepções de professores, tanto em formação inicial como em formação continuada, influenciam o modo como o professor utiliza as analogias em sala de aula. Dessa forma, analisar o discurso acerca das analogias de professores é uma tendência nas pesquisas que versam sobre o tema.

Recentemente, Santos e Santana (2018) realizaram um estado da arte, no qual quantificaram as publicações referentes ao uso de analogias, em três eventos importantes da área de ensino de Ciências e Educação. Como resultado, obtiveram 92 publicações referentes ao período de 2000 a 2016, os quais foram alocados em seis linhas investigativas: utilização e exploração didática de analogias; analogias em manuais escolares; analogias na prática dos professores de Ciências; analogias e as concepções de professores sobre o seu papel no processo de ensino e aprendizagem; analogias e os estudos de revisão; analogias e ensino.

Do total de pesquisas encontradas (92), apenas oito foram alocadas na linha de investigação sobre as concepções de professores. Com base nesse resultado, pode-se inferir que novas pesquisas permitiram avaliar se discussões acerca das analogias permeiam a formação inicial e continuada. Caso estas discussões se façam presentes, suas concepções podem indicar de que modo eles se apropriaram da temática, e de que modo as utilizam em sala de aula.

\section{ASPECTOS METODOLÓGICOS}

A opção metodológica que orientou esta pesquisa se fundamenta na abordagem qualitativa, uma vez que essa abordagem busca, essencialmente, compreender as concepções, atitudes e comportamentos a partir da perspectiva dos participantes da investigação (BOGDAN; BIKLEN, 1994). Entre a multiplicidade de métodos que a pesquisa qualitativa possui, para este estudo se optou pelo método de tipo Estudo de Caso, pois se trata de um método com viés focado no estudo de uma particularidade, no qual o pesquisador tem interesse de estudar um caso específico e permite com que os pesquisadores retenham as características holísticas e significativas dos eventos da vida real (YIN, 2015).

Considerando os pressupostos da pesquisa qualitativa, o percurso metodológico adotado consistiu em quatro etapas simultâneas e interdependentes: a exploratória, a elaboração e a aplicação dos instrumentos de pesquisa, e a análises e conclusões.

$\mathrm{Na}$ fase exploratória foi realizada uma pesquisa de cunho bibliográfico em livros e artigos científicos, bem como uma análise das obras aprovadas pelo Programa Nacional do Livro e Material Didáticos (PNLD) 2018-2020, com a finalidade de analisar como as analogias são compreendidas no contexto escolar, seja por professores ou em livros didáticos no processo de ensino e aprendizagem de conceitos químicos. 


\section{Educação Química}
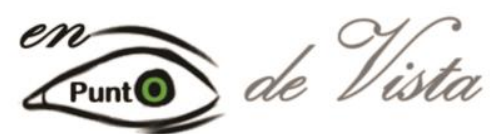

\section{Chemical Education in Point of View}

https://revistas.unila.edu.br/eqpv

A elaboração do instrumento de pesquisa ocorreu com a organização de um questionário autoaplicável online e a elaboração de um roteiro de entrevista semiestruturada. A opção pelo questionário, como um instrumento de coleta de dados, foi por este apresentar grandes possibilidades de investigação, permitindo assim conhecer e analisar melhor tanto o contexto escolar em que os participantes da pesquisa estão inseridos, quanto suas opiniões e anseios sobre o objeto analisado. Já a opção pela entrevista ocorreu pela possibilidade de se estabelecer uma interação com o entrevistado, como destaca Gil (2008, p. 109): "entrevista é, portanto, uma forma de interação social" e, essa interação se constitui como um fator importante no processo de elaboração e apresentação das respostas do entrevistado, tornando-as, segundo Yin (2015), espontâneas.

Quanto ao questionário, este foi organizado na plataforma Google Formulários, seguido do envio aos endereços eletrônicos dos participantes da pesquisa. Para tanto, o questionário foi estruturado com quatro questões: 1. O que você entende por analogia? 2. Você utiliza analogias em suas aulas? Quais? 3. Quais as vantagens e desvantagens ao usar as analogias em sala de aula? 4. Você percebe alguma diferença entre analogias e metáforas? Se sim, quais?

A entrevista semiestruturada se constituiu na tentativa de aprofundar as respostas dadas pelos sujeitos, por sua vez, foi organizada em dois blocos, sendo o primeiro composto por depoimentos sobre a atuação profissional participante, e o segundo com os depoimentos sobre as analogias como estratégia de ensino, em que os participantes tiveram a oportunidade de contar, espontaneamente, como ocorre o planejamento teórico, prático e estratégico ao ensinar os conceitos químicos com auxílio das analogias.

Em relação à aplicação dos instrumentos de coleta de dados, participaram da pesquisa seis professores, todos licenciados em Química, que ministram aulas da disciplina de Química, em diferentes cidades, na rede pública de ensino do Estado de Mato Grosso. Com a autorização expressa e consentida, os professores responderam o questionário e a entrevista. A escolha dos participantes decorre de serem estes egressos do Programa de Pós-Graduação de Ensino de Ciências Naturais da Universidade Federal de Mato Grosso, por atuarem e/ou já terem atuado na Educação Básica como professores de Química e por terem em algum momento da docência recorrido ao uso de analogias no ensino.

A coleta de dados ocorreu durante o momento de planejamento dos professores, após terem encerrados suas atividades no curso de Pós-Graduação, com o intuito de que esses dispusessem de tempo hábil para refletir e buscar em suas recordações as experiências vivenciadas no tocante ao objeto de estudo. Assim, se obteriam informações mais ricas, que possibilitaram a organização das demais atividades de forma a atender as demandas formativas apresentadas pelos participantes da pesquisa.

Por fim, para a análise dos registros de informações se recorreu à Análise Textual Discursiva (ATD), proposta por Moraes e Galiazzi (2011). Segundo estes autores, a ATD, fundamenta-se em torno de quatro etapas, são elas: desmontagem dos textos (unitarização), 


\section{Educação Química}
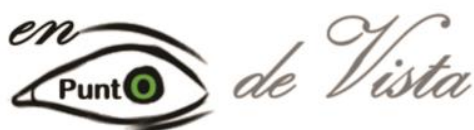

Chemical Education in Point of View

https://revistas.unila.edu.br/eqpv

estabelecimento de relações (categorização) e captação do novo emergente (metatexto). A escolha pela ATD se justifica porque este método permite uma análise rigorosa e síntese subsequente, possibilitando a construção de novos conhecimentos, de forma a ampliar os significados do fenômeno pesquisado. Assim, as análises e conclusões ocorreram com base em um tratamento predominantemente qualitativo das informações obtidas dos questionários e entrevistas, relacionando-as com os saberes pedagógicos ${ }^{2}$ dos professores acerca do uso das analogias como recurso didático nas aulas de Química.

\section{RESULTADOS E DISCUSSÕES}

Nesta seção são apresentados os resultados e as possíveis discussões em função dos dados coletados. Para as questões 1, 3, 4 foi possível elencar categorias elaboradas a posteriori. Para tanto, as respostas foram agrupadas em quatro quadros.

Para a questão (o que você entende por analogia?) Quatro concepções de analogias se fizeram presentes e estas refletem a polissemia do termo, como mostrado no quadro 1.

Quadro 2- Concepções dos professores referentes às analogias.

\begin{tabular}{|c|l|}
\hline Categorias & \multicolumn{1}{|c|}{ Respostas } \\
\hline Analogias como modelos & $\begin{array}{l}\text { P1: são modelos que se assemelham ao assunto que será } \\
\text { trabalhado. }\end{array}$ \\
\hline Analogias como exemplos & $\begin{array}{l}\text { P2: usar exemplos semelhantes com o conteúdo que se está } \\
\text { trabalhando [...]. } \\
\text { P4: exemplos que podem ser utilizados para representar algo ou } \\
\text { alguma coisa. }\end{array}$ \\
\hline Analogias como explicação & $\begin{array}{l}\text { P3: a analogia é entendida como algo que explica o desconhecido } \\
\text { utilizando o conhecido. }\end{array}$ \\
\hline Analogias como & $\begin{array}{l}\text { P5: são formas de representar conceitos, comparando-os com } \\
\text { situações conhecidas pelos estudantes, mesmo que estas situações } \\
\text { não sejam conceitualmente relacionadas. } \\
\text { P6: relação de semelhança. }\end{array}$ \\
\hline
\end{tabular}

Fonte: Produção dos autores (2020).

$\mathrm{Na}$ categoria analogias como modelos, o professor P1 definiu analogia se referindo ao conceito de modelo. Essa associação pode ser justificada pelo fato de que tanto as analogias como os modelos são dispositivos da linguagem, e ambos podem funcionar para comunicar algo e são empregados com o intuito de facilitar esta comunicação.

\footnotetext{
${ }^{2}$ Os saberes pedagógicos são constituídos de saberes da experiência, dos saberes do conhecimento e os saberes didáticos e pedagógicos, ou seja, são os saberes construídos pelo professor na prática cotidiana, na prática docente, que por sua vez, contribuem com a formação profissional, a medida que entende as particularidades do trabalho docente e, assim, construir sua identidade de professor (PIMENTA, 2012). É no exercício da docência que o professor constrói os saberes pedagógicos, uma vez que esses saberes se relacionam ao como ensinar.
} 


\section{Educação Química}
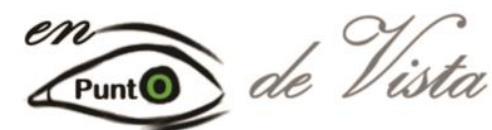

Chemical Education in Point of View

https://revistas.unila.edu.br/eqpv

Mól (1999, p.56) afirma que: "as metáforas e os modelos são formas diferentes de comparações e, portanto, devem ser consideradas como tal". Para este autor, os modelos: "são comparações explícitas feitas entre um conceito alvo e uma imagem ou objeto que o represente" (MÓL, 1999, p.64). Nesse sentido, os modelos podem se apresentar na forma de uma imagem ou de um objeto.

Normalmente, para estudar um determinado fenômeno complexo são criados vários modelos, por exemplo, a analogia do Sistema Solar, pode-se ter uma ideia do átomo, não só estabelecendo comparações entre os dois domínios, mas desenvolvendo modelos pictóricos como o proposto por Rutherford (RIGOLON, 2008). É interessante ainda considerar as analogias como comparações e os modelos como representações, para que não haja confusões.

Para os professores P2 e P4, as analogias estão no mesmo patamar que os exemplos. Em entrevista, P2 confirma sua concepção ao narrar que as analogias: "são palavras ou objetos que nos utilizamos como exemplos para poder exemplificar alguma coisa para alguém". Esta confusão é recorrente, uma vez que os dois (exemplos e analogias) são amiúde utilizados para retratar aspectos de um conceito em estudo. Entretanto, o exemplo se enquadra em conceitos que pertencem ao mesmo domínio, enquanto as analogias correlacionam conceitos de domínios diferentes (DUARTE, 2005).

Segundo González González (2002), os exemplos servem para finalidades semelhantes aos das analogias no processo de ensino e aprendizagem, pois ambos são usados para relacionar o cotidiano ao desconhecido. Entretanto, um exemplo é um caso particular de constatação ou de ilustração de uma situação ou fenômeno, o que não é o caso da analogia. Por exemplo, ao citar o cachorro (animal) como um exemplo de mamífero, o professor quer dizer que dentro da categoria dos mamíferos, o cachorro é um dos seus representantes. Logo, tanto a categoria de o representante está no mesmo domínio do que é a Mastozoologia.

O equívoco dos professores, quando associam analogia com exemplo, ou com outras formas de comparações, foram constatados em outras pesquisas. As pesquisas desenvolvidas por autores como Almeida e Lorencini-Júnior (2018); Duarte (2005) e Mozzer e Justi (2015) apresentam que os professores, mesmo com ampla experiência de docência, possuem dificuldades para diferenciar analogias de exemplos.

Na categoria analogias como explicação, P3 relata que a analogia é entendida como algo que explica o desconhecido utilizando o conhecido. Embora restrito, este raciocínio está próximo do apresentado na literatura. Como visto, uma analogia é uma relação de similaridade entre dois domínios em decorrência de semelhanças presentes em cada domínio. Portanto, há uma variedade de relações que podem ser estabelecidas entre dois domínios.

Nesse âmbito, FERRAZ (2006), em sua pesquisa, classifica as analogias utilizadas por professores com base no nível de organização. A classificação das analogias depende do atributo dos domínios que serão comparados, como a forma ou a função, de como são enunciadas, da quantidade de atributos em comparação e de como são trabalhadas pelo professor. 


\section{Educação Química}
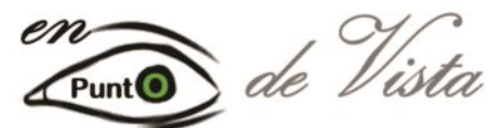

Chemical Education in Point of View

https://revistas.unila.edu.br/eqpv

Os professores P5 e P6 demonstraram, em suas narrativas, terem um bom entendimento do que seria uma analogia, uma vez que eles as associaram com o conceito comparação (P5) ou de relações de semelhanças (P6).

Os termos comparações e relação de semelhanças estão próximos das definições encontradas na literatura. Conforme apresentado anteriormente, as analogias são comparações de similaridades relacionais entre um domínio familiar (análogo) e outro desconhecido ou pouco conhecido (alvo). As analogias diferem das demais formas de comparações, de acordo com a correspondências dos domínios a serem comparados e sua posterior explicação (MOZZER; JUSTI, 2015).

Na questão intitulada (você utiliza analogias em suas aulas? Quais?) se percebe que alguns exemplos apresentados pelos professores são comuns aos livros didáticos, como as tradicionais analogias encontradas nos Modelos Atômicos, conforme narra o professor P5: "Sim, geralmente quando trabalho o conteúdo de atomística, estrutura atômica, modelos atômicos: bola de bilhar, pudim de passas, sistema solar, campo e bola de futebol, andares de edifícios [...]".

Embora não ter dito a origem destas analogias, comumente são encontradas nos livros didáticos. Esse dado reforça a importância do livro didático para as práticas do professor, uma vez que pode ser a principal fonte utilizada por ele para lecionar.

Mozzer e Justi (2000), na pesquisa que buscou avaliar as analogias presentes nos livros didáticos de Química, concluem que em geral, por desconhecer o potencial das analogias como recurso de ensino, os autores dos livros didáticos fazem o uso pouco expressivo de analogias e, nas analogias encontradas, os autores não apresentam as similaridades e as diferenças entre a analogia e o conceito científico em comparação. Assim, se os livros trazem apenas analogias simples, ou seja, as que não fazem o mapeamento dos atributos do domínio alvo e do análogo, caso o professor não tenha tido discussões dessa natureza em sua formação, é provável que o mesmo continue as utilizá-las ao invés das analogias enriquecidas ou estendidas caracterizadas por utilizar um grupo ou vários atributos para descrever o conceito alvo, respectivamente (FERRAZ, 2006).

Além das analogias tradicionais retratadas, $\mathbf{P} \mathbf{2}$ ao explicar os conceitos de Diluição de soluções, ao dizer para os estudantes "pensar que a sala de aula é o recipiente que contém todo o solvente e que os alunos são o soluto. Peço para imaginarem o que acontece se aquele número de alunos estiver numa sala maior ou menor, compara a sala de aula com o solvente e os estudantes como o soluto de uma solução.

P4 nos conceitos que envolvem a Termoquímica, compara o processo exotérmico (reações que liberam energia) com fim de um relacionamento "de que ex nós queremos liberar na nossa vida". Um aspecto importante apresentado pelos professores (P2 e P4) é o fato deles realizarem as comparações com episódios próximos dos estudantes. Neste sentido, Justi e Mendonça (2008) corroboram ao dizer que para que as analogias possam facilitar a aprendizagem o professor deve recorrer ao seu uso quando o conceito alvo é de difícil compreensão pelos estudantes e as relações entre os conceitos alvo e análogo devem ser de 


\section{Educação Química}

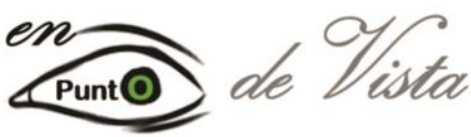

Chemical Education in Point of View

https://revistas.unila.edu.br/eqpv

(c) (i) ()

fácil compreensão pelos estudantes. Além disso, as analogias devem ser claras e facilmente lembradas.

Outra analogia citada por P2 se refere aos conceitos que envolvem o conteúdo de Eletroquímica, no qual a compara corrente elétrica com "elétrons correndo pelo fio". O professor associa esta analogia com representações animistas. Analogias deste tipo podem desencadear concepções errôneas que os estudantes podem apresentar a partir do seu uso. Segundo Santos (2011), para evitar dificuldades no aprendizado de Química, é necessária uma linguagem mais precisa, é importante evitar analogias animistas, que tratam, por exemplo, átomos e moléculas como seres vivos.

P3, diz que ao abordar os conceitos de Equilíbrio Químico recorre à analogia do aquário. Esta analogia compara o movimento dos peixes entre dois aquários (análogo) com a situação de equilíbrio numa reação (alvo). Dado que os aquários são de tamanhos iguais o equilíbrio é alcançado quando há o mesmo número de peixes em cada um. Esta analogia merece atenção pois, conforme destaca Raviolo e Garritz (2007), a mesma contribui para que os estudantes tenham imagem errada de que os reagentes e produtos se encontram em diferentes recipientes.

Com base nos exemplos de analogia apresentados, percebe-se que todos os conteúdos citados envolvem conceitos que pertencem às entidades microscópicas da Química, as quais são mais propensas ao uso de analogias. Nessa perspectiva, Francisco Júnior (2010) corrobora ao dizer que as analogias mediatizam a compreensão do nível microscópico e auxiliam a introdução dessa nova linguagem (científica) repleta de símbolos e características peculiares, diferente da linguagem comum.

A terceira pergunta buscou compreender se os professores visualizam vantagens ao utilizarem analogias em suas aulas. As respostas foram alocadas na categoria facilita a compreensão, conforme o quadro 2.

Quadro 3- Concepções dos professores referentes às vantagens das analogias

\begin{tabular}{|l|l|}
\hline Categoria & \multicolumn{1}{|c|}{ Vantagens } \\
\hline \multirow{5}{*}{ Facilita a compreensão } & P1: Demais, pois na Química nem tudo é visível, ou de fácil \\
& compreensão, mas quando há uma idealização do desconhecido \\
pautado naquilo que já é conhecido, facilita o entendimento. & P2: Eu acredito que sim por facilitar a visualização daquela coisa tão \\
& abstrata. \\
& P4: Os alunos costumam lembrar depois. [...] eu digo que facilita a \\
& memorização. \\
& P6: Eu acho que analogia acaba que o aluno fixa mais o conceito, não é \\
& que o aluno vá decorar, mas assim, ele tem uma busca mais rápida \\
& daquele conceito. \\
& P3: Eu acho que motiva o aluno né, porque são matérias abstratas \\
então facilita a compreensão e a interpretação de questões abstratas.
\end{tabular}

Fonte: Produção dos autores (2020).

De acordo com as respostas apresentadas no questionário, para maioria dos professores, uma das vantagens de utilizar analogias é o fato dessas facilitarem o entendimento dos conceitos químicos pelos estudantes, uma vez que se trata de uma Ciência abstrata. 


\section{Educação Química}
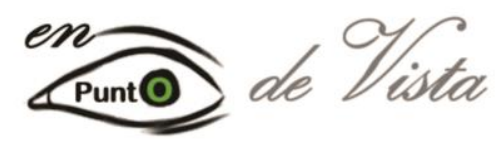

Chemical Education in Point of View

https://revistas.unila.edu.br/eqpv

A concepção de que o uso de analogias facilita a aprendizagem de conceitos científicos, por parte dos estudantes, está em consonância com diversos trabalhos da área, por exemplo o de Ferraz e Terrazzan (2002), os quais consideram as analogias como um instrumento que auxilia na construção do conhecimento, portanto, ferramentas pedagógicas relevantes para o ensino de Ciências. Isso porque as analogias, desde que utilizadas corretamente, possibilitam a transposição didática, pois propiciam uma melhor compreensão do fenômeno em estudo (ALMEIDA, 2016).

Assim, o conhecimento complexo se torna simples no intuito de se tornar mais concreto e tangível para o aluno. Outros pesquisadores, como: Bozelli (2005), Duarte (2005) e Mozer e Justi (2018), corroboram com este pensamento e ressaltam que as analogias tornam o conhecimento científico plausível aos estudantes.

Nessa perspectiva, as expressões do tipo: facilitam a memorização, motiva os estudantes $e$ facilita a visualização/entendimento do estudante, atribuem às analogias um aspecto positivo para o uso desse recurso por parte dos professores, pois, por meio das analogias, o professor aproxima um conceito complexo de ser compreendido com a realidade do estudante, com isso melhora a compreensão dos conceitos, tornando o ensino mais dinâmico e prazeroso aos envolvidos.

As vantagens apresentadas pelos participantes podem ser ampliadas. Segundo Duarte (2005), a utilização das analogias leva à ativação do raciocínio analógico, organizando as percepções, desenvolvendo as capacidades cognitivas e podendo, também, avaliar os conhecimentos e a compreensão dos estudantes.

Embora apresentem as vantagens apresentadas anteriormente, também foram apontados alguns perigos que são inerentes ao uso indiscriminado das analogias. Assim, quando questionados sobre os perigos existentes na utilização de analogias, foram obtidas respostas que se encontram distribuídas na categoria obstáculos à aprendizagem, conforme se apresenta no quadro 3.

Quadro 4- Concepções dos professores referentes aos perigos das analogias.

\begin{tabular}{|l|l|}
\hline \multicolumn{1}{|c|}{ Categoria } & \multicolumn{1}{c|}{ Perigos } \\
\hline \multirow{5}{*}{$\begin{array}{l}\text { Obstáculos } \\
\text { aprendizagem }\end{array}$} & $\begin{array}{l}\text { P1: Sim. O perigo de o aluno pensar que a analogia é a coisa em si. } \\
\text { P3: Os alunos tendem a associar esse conteúdo a analogia e perdem o } \\
\text { sentido científico. } \\
\text { P5: Sim, pois os estudantes podem compreender a analogia (o exemplo) em } \\
\text { si, mas não conseguirem relacionar com o conteúdo/conceito em estudo, } \\
\text { produzindo obstáculos epistemológicos e pedagógicos à aprendizagem [...]. } \\
\text { P6: [...] se você não deixa claro sem o planejamento, acho que prejudica } \\
\text { por que o aluno vai confundir e não vai entender o conceito químico. } \\
\text { P2: Sim. Os alunos podem compreender o conteúdo errado, construindo } \\
\text { visões deformadas e obstáculos epistemológicos na aprendizagem. } \\
\text { P4: Sim, pois uma analogia utilizada de forma incorreta pode ao invés de } \\
\text { ajudar o aluno a entender, prejudicar a aprendizagem. }\end{array}$ \\
\hline
\end{tabular}

Fonte: Produção dos autores (2020). 


\section{Educação Química}
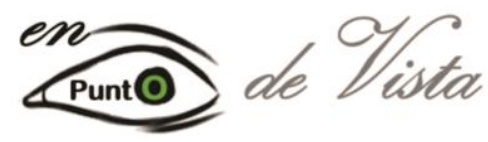

Chemical Education in Point of View

https://revistas.unila.edu.br/eqpv

É possível a existência de todos esses perigos apresentados pelos professores em relação ao uso de analogias, somados a esses Duarte (2005) ressalta que, se não for dada a devida atenção no momento do uso desse tipo de recurso didático, corre-se o risco da analogia ser interpretada como o conceito em estudo, e pode criar concepções alternativas e errôneas nos estudantes e, assim, não atingir os objetivos de ensino. Entretanto, vale ressaltar que para que seja um recurso eficaz é necessário que os professores adotem os cuidados necessários ao trabalhar com analogias.

Os professores P2, P4 e P5 expressaram, em entrevista, receio de usarem as analogias em suas aulas, como visto em suas narrativas:

P2: [...], mas aí depois de ter estudado a respeito dos obstáculos epistemológicos, eu fico muito receosa, eu vou tomar muito mais cuidados para não criar esses obstáculos na cabeça dos meus alunos, atrapalhar a compreensão deles.

P4: Eu tenho um pouco de receio de utilizar justamente para não, muitas vezes a gente acredita que tá facilitando a aprendizagem e não está.

P5: [...] e eu tenho receio de utilizar analogia por não ter um domínio 100 por cento, apesar que eu acredito que eu tenha, mas eu acho que é um recurso importante, mas que tem que ser bem utilizado.

Percebe-se, em suas narrativas, que um dos receios de usarem analogias, em suas aulas, é porque estas podem criar obstáculos na aprendizagem dos estudantes. Essa preocupação é muito comum, uma vez que se trata de professores egressos do mestrado profissional no qual muitas vezes, participaram de intensas discussões sobre as vantagens bem como os perigos inerentes aos recursos didáticos para o Ensino de Ciências. Dessa forma, concorda-se com Ferraz e Terrazzan (2002), ao dizer que se os professores fossem instruídos para o uso de analogias poderiam utilizálas sem medo algum em suas aulas.

Com o intuito de saber se os professores confundem analogia com outros termos parecidos foi perguntado se percebiam diferenças entre analogias e metáforas. As respostas foram categorizadas e descritas no quadro 4.

Quadro 5- Concepções dos professores referentes às diferenças entre analogias e metáforas.

\begin{tabular}{|l|l|}
\hline \multicolumn{1}{|c|}{ Categorias } & \multicolumn{1}{|c|}{ Diferença entre analogias e metáforas } \\
\hline Diferença imprecisa & $\begin{array}{l}\text { P1: Sim. Analogias são coisas semelhantes e metáforas são sentidos } \\
\text { semelhantes. } \\
\text { P2: Sim. Analogia é usar um exemplo com características semelhantes. } \\
\text { Metáfora é usar figuras de linguagem, acho que é natural na fala do professor. }\end{array}$ \\
\hline Diferença coerente & $\begin{array}{l}\text { P3: As analogias são comparações entre duas estruturas enquanto que nas } \\
\text { metáforas a apresentação é mais direta. Ex. pudim de passas. } \\
\text { P5: Principalmente na forma em que são explicitadas. }\end{array}$ \\
\hline Não têm diferenças & $\begin{array}{l}\text { P4: Não. } \\
\text { P6: Não. }\end{array}$ \\
\hline
\end{tabular}

Fonte: Produção dos autores (2020). 


\section{Educação Química}
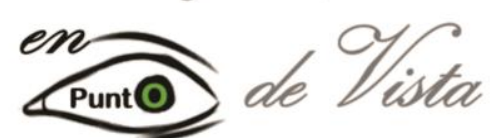

\section{Chemical Education in Point of View}

https://revistas.unila.edu.br/eqpv

Todos os professores, exceto P4 e P6, acreditam que os termos possuem diferenças.

Dois professores, P3 e P5, apresentaram concepções que se aproximam das definições de metáforas e analogias encontradas na literatura. P3 consegue associar as metáforas como uma comparação direta. Apesar de breve a resposta, P5 apresenta uma característica importante que diferencia as analogias das metáforas: na forma em que são explicitadas.

No sistema de comparação realizado por Mól (1999), ambas comparam dois domínios, entretanto, as metáforas são comparações implícitas e as analogias são explícitas. A existência dos conectivos de comparação (como, parece, semelhante, lembra, entre outros) é uma forma de reconhecer uma analogia. Por exemplo, quando o professor diz que o modelo do átomo proposto por Dalton é uma bola de bilhar, ele utiliza uma metáfora (comparação implícita), pois ele está afirmando que o átomo é uma bola de bilhar, obviamente que o átomo não é uma bola de bilhar. Ao dizer que o átomo proposto por Dalton é semelhante a uma bola de bilhar, ele utiliza uma analogia, pois o professor compara explicitamente o alvo (átomo de Dalton) com um análogo (bola de bilhar).

Na categoria diferença imprecisa, as respostas dos professores P1 e P2 são permeadas por definições confusas. Como menciona Oliva (2008), em relação ao uso das analogias, em sala de aula, um dos saberes a serem apropriados, pelos professores de Ciências, é o saber diferenciar de outros tipos de comparações (modelos e metáforas). Em se tratando do processo de ensino e aprendizagem é importante que os professores superem essa confusão para que assim as analogias sejam utilizadas de forma correta em sala de aula.

\section{CONSIDERAÇÕES}

A investigação forneceu subsídios para acessar as concepções expressas, pelos professores participantes desta pesquisa, acerca das analogias. Com relação à definição das analogias, os resultados mostraram que apesar de alguns compreenderem o conceito, outros afirmaram não saber que as comparações que muitas vezes utilizavam, em suas aulas, se tratavam de analogias e não de modelos ou exemplos. Por outro lado, com relação às vantagens desse recurso, os professores expressaram fundamentalmente que as analogias se constituem como importante recurso didático, com bom potencial de auxílio no processo de ensino e aprendizagem, desde que bem planejadas, uma vez que a sua utilização diminui a abstração e facilita a compreensão dos conceitos a serem ensinados, isso porque as analogias aproximam dois domínios, um conhecido e outro ainda desconhecido pelos estudantes.

Foi possível constatar que os professores se mostraram confusos e/ou desconhecem a diferença entre as analogias e as metáforas. Segundo Oliva (2008), há um grupo de saberes em que os professores de Ciências devem se apropriar ao utilizar as analogias em suas aulas, entre esses: o saber sobre analogia, no qual envolve distingui-las de outros recursos, justificar o seu interesse para a comunicação humana e para o ensino de Ciências, conhecer analogias históricas e a sua importância para a construção do pensamento científico, conhecer os mecanismos de 


\section{Educação Química}
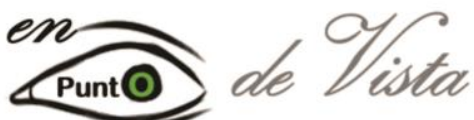

\section{Chemical Education in Point of View}

https://revistas.unila.edu.br/eqpv

aprendizagem por analogias, entre outros. Assim, saber diferenciar as analogias de outros tipos de comparações é fundamental para um primeiro movimento. Os demais saberes poderão ser trabalhados na sequência.

Se por um lado as analogias facilitam a compreensão dos conceitos científicos pelos estudantes, por outro lado a má utilização desse recurso pode desencadear graves problemas ao processo de ensino e aprendizagem. Nessa perspectiva, os professores mostraram conhecer as vantagens, bem como os perigos inerentes ao uso das analogias, e a este caso se pode atribuir ao fato de serem egressos do Programa de Pós-Graduação em Ensino de Ciências Naturais, no qual muitas vezes participavam de discussões sobre os riscos e vantagens de determinados recursos didáticos para o Ensino de Ciências e por terem sido iniciados nas discussões sobre Bases Epistemológicas para o Ensino de Ciências.

Por fim, os resultados desta pesquisa apontam para importância de inserir discussões relativas ao uso de analogias em ambientes de formação de professores, ressaltando a sua função, suas utilidades, suas vantagens e desvantagens, enfim, procurando sanar possíveis dificuldades quanto a este recurso. Ao ter conhecimentos relacionados ao uso das analogias, os professores estarão aptos para incluí-las em seu planejamento, bem como utilizá-las de forma estruturada, contribuindo para que seu uso contemple a sua função, a de facilitar a compreensão de assuntos abstratos a partir do que é familiar aos estudantes.

\section{REFERÊNCIAS}

ALMEIDA, H. A. As analogias utilizadas por professores de Biologia como elementos da transposição didática. 197 p. Mestrado em Educação para a Ciência e a Matemática, Universidade Estadual de Maringá, Maringá, 2016.

ALMEIDA, H. A.; LORENCINI-JUNIOR, A. As concepções de um professor de Biologia quanto ao uso de analogias na prática docente. ACTIO, Curitiba, v. 3, n. 2, p. 173-194, mai./ago. 2018.

BOGDAN, R. C.; BIKLEN, S. K. Investigação qualitativa em educação. Tradução Maria João Alvarez, Sara Bahia dos Santos e Telmo Mourinho Baptista. Porto: Porto Editora, 1994.

BIZZO, N. Perspectivas para a atuação do Professor - Ciências: fácil ou difícil? 2. ed. São Paulo: Ed. Ática, 2002, p.14.

BOZELLI, F. C.; NARDI, R. Interpretações sobre o conceito de metáforas e analogias presentes em licenciandos de Física. Enseñanza de las ciencias. Barcelona: n. extra, p. 1-5, 2005.

Discurso analógico no Ensino Superior. In: R. Nardi e M.J.P.M. Almeida. (Ed.), Analogias, leituras e modelos no ensino da ciência: A sala de aula em estudo. São Paulo: Escrituras, 2006. p.11-28. 


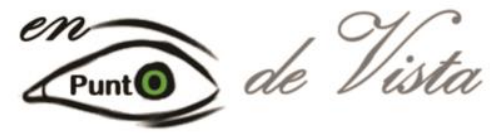

CACHAPUZ, A. Linguagem metafórica e o ensino das ciências. Revista Portuguesa de Educação, 2(3): 117-129, 1989.

CARVALHO, D. S.; SILVEIRA, M. R. A. Jogos de linguagem na perspectiva de Wittgenstein evidenciados em atividades de modelagem matemática. Revista de Ensino de Ciências e Matemática, v. 10, n. 5, p. 171-190, 2019.

COELHO, C. K. G; COIMBRA, D. C. S. LANDGRAF-VALERIO, C. L.; VILELA, M. V. F. Percepções da relação professor/livro didático e as formas de utilização de seus recursos na Escola Estadual São Lourenço, Dom Aquino-MT. Revista Monografias Ambientais, v. 14, p. 53-68, 2015.

DUARTE, M. C. Analogias na Educação em Ciências Contributos e Desafios. Investigações em Ensino de Ciências, v. 10, n. 1, 2005.

DUIT, R. Sobre o papel das analogias e metáforas na ciência da aprendizagem. Science Education, 75(6), 649-672, 1991.

FERRAZ, D. F. O uso de analogias como recurso didático por professores e biologia no ensino médio. Cascavel: edunioeste, 2006.

FERRAZ, D. F.; TERRAZZAN, E. A. O uso espontâneo de analogias por professores de biologia: observações da prática pedagógica. Ensaio-pesquisa em educação em ciências, v. 4, n. 2, p. 1-15, dez. 2002.

FERRY, A. S.; NAGEM, R. L. Analogias \& contra-analogias: uma proposta para o ensino de ciências numa perspectiva bachelardiana. Experiências em Ensino de Ciências, vol.3, n.1, p.7-21, 2008.

FLÔR, C. C. Leitura e Formação de Leitores em Aulas de Química no Ensino Médio. Tese (2009). Doutorado em Educação Científica e Tecnológica. Universidade Federal de Santa Catarina. p. 203.

FRANCISCO JUNIOR, W. E. Analogias e situações problematizadoras em aulas de ciências. São Carlos: Pedro \& João Editores, 2010.

GARRITZ, A.; RAVIOLO, A. Analogias no ensino de equilíbrio químico. Revista Química Nova na Escola, n. 27, 2008.

GIL, A. C. Métodos e técnicas de pesquisa social. 6. ed. Editora Atlas SA, 2008.

GONZALEZ GONZALEZ, B. M. Las analogías en el proceso enseñanza - aprendizaje de las ciencias de la naturaleza. 650 p. Doutorado em Didatica das Ciencias Experimentais, Universidad de La Laguna, La Laguna, 2002. 


\section{Educação Química}

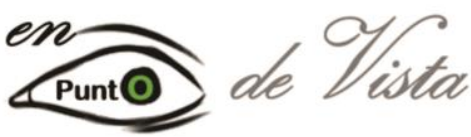

Chemical Education in Point of View

https://revistas.unila.edu.br/eqpv

JUSTI, R. S; MENDONÇA, P. C. C. Usando analogias com função criativa: uma nova estratégia para o ensino de química. Educació química, 1(1), 24-29, 2001.

. Usando analogias com função criativa: uma nova estratégia para o ensino de química. Educació química, p. 24-29, 2008.

MÓL, G. O Uso de analogias no ensino de Química. 1999. 254 f. Tese (Doutoramento em Química) - Instituto de Química, Universidade de Brasília, Brasília, 1999.

MORAES, R.; GALIAZZI, M. C. Análise Textual Discursiva. Ijuí: Ed. Unijuí, 2011.

MOZZER, N. B.; JUSTI, R. Analogias em Livros Didáticos de Química Brasileiros Destinados ao Ensino Médio. 5 (2): 67-91, 2000.

. "Nem tudo que reluz é ouro": Uma discussão sobre analogias e outras similaridades e recursos utilizados no ensino de Ciências. Revista Brasileira de Pesquisa em Educação em Ciências, v.15, n. 1, p. 123-147, 2015.

. Modelagem analógica no ensino de Ciências. Investigações em Ensino de Ciências-v. 23, n. 1, p. 155-182, 2018.

OLIVA, J. M.; ARAGÓN, M. M.; MATEO, José; BONAT, M. Una propuesta didáctica basada en la investigación para el uso de analogías en la enseñanza de las ciencias. Enseñanza de las Ciencias Vigo, Espanha, v. 19, n. 3, p. 453-470, 2001.

OLIVA, J. M. Qué conocimientos profesionales deberíamos tener los profesores de ciencias sobre el uso de analogias. Rev. Eureka Enseñ. Divul. Cien. v. 5, n. 1, p. 15-28, 2008.

RIGOLON, R. G. O conceito e o uso de analogias como recurso didático por licenciandos de Biologia. 2008. 132 f. Dissertação (Mestrado em Educação para as Ciências e o Ensino de Matemática) -Universidade Estadual de Maringá, Maringá, 2008.

RIGOLON, R. G.; OBARA, A. T. O conceito de analogias por licenciandos de Biologia. Rev. Teoria e Prática da Educação, v. 13, n. 3, p. 19-31, set./dez. 2010.

SANTOS, W. L. P. Popularização do ensino de química para a vida e para justiça social, 2011. Disponível em: https://www.dicyt.com/noticia/popularizacao-do-ensino-de-quimica-para-a-vidae-para-a-justica-social.

TREAGUST, D.; DUIT, R.; JOSLIN, P.; LINDAUER, I. Science Teacher's Use of Analogies: Observations from Classroom Practice. International Journal of Science Education, v.14, n.4, p. 413-422, 1992.

YIN, R. K. Estudo de Caso: planejamento e métodos. 4.ed. Tradução Daniel Grassi. Porto Alegre: Bookman, 2010. 


\section{Educação Química}

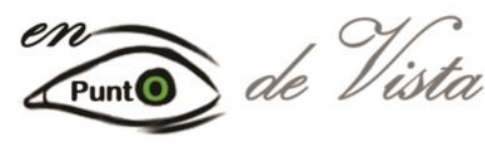

Chemical Education in Point of View

https://revistas.unila.edu.br/eqpv

ZAMBON, L. B.; TERRAZZAN, E. A. Analogias produzidas por alunos do Ensino Médio em aulas de Física. Revista Brasileira de Ensino de Física. v. 35, n. 1, 1505. 2013.

\section{RESUMO}

As analogias se configuram como um importante instrumento para a compreensão dos conceitos complexos em sala de aula. Além disso, o uso de analogias pode facilitar o processo de apropriação de novos conceitos, uma vez que essa estratégia de ensino estabelece comparações entre dois domínios, um conhecido e outro desconhecido. Mediante o papel ocupado por este instrumento, é necessário conhecer as prévias concepções dos professores acerca do tema. Para isso, foi realizado um estudo de natureza qualitativa, por meio do Estudo de Caso, tendo como instrumento de coleta o questionário e entrevista semiestruturada, aplicado a seis professores egressos de Mestrado Profissional em Ensino de Ciências da área de Química. Como resultado foram percebidas algumas dificuldades, como: conceituar as analogias e diferenças entre as analogias e as metáforas. Desse modo, evidenciou-se a necessidade da inserção de discussões sobre o uso de analogias no ensino, ressaltando sua função, suas utilidades, suas vantagens e desvantagens.

\section{RESUMEN}

Las analogías se configuran como una herramienta importante para comprender conceptos complejos en el aula. Además, el uso de analogías puede facilitar el proceso de apropiación de nuevos conceptos, ya que esta estrategia de enseñanza establece comparaciones entre dos dominios, uno conocido y el otro desconocido. Debido al papel desempeñado por este instrumento, es necesario conocer las concepciones previas de los maestros sobre el tema. Para ello, se realizó un estudio cualitativo, a través del Caso de Estudio, utilizando el cuestionario y la entrevista semiestructurada como instrumento de recopilación, aplicado a seis profesores que se graduaron de la maestría profesional en Enseñanza de Ciencias en el área de Química. Como resultado, se notaron algunas dificultades, como conceptualizar analogías y diferencias entre analogías y metáforas. Así, se hizo evidente la necesidad de insertar discusiones sobre el uso de analogías en la enseñanza, enfatizando su función, sus usos, sus ventajas y desventajas. Palabras clave: Enseñanza de las Ciencias; Analogías; Enseñanza de la química. 